\title{
Commitment, Types of Dialogue, and Fallacies
}

\author{
DOUGLAS WALTON University of Winnipeg
}

Key Words: Fallacies, dialogue, ad hominem, slippery slope, argumentation, maieutic function, dark-side commitments.

Abstract: This paper, based on research in a forthcoming monograph, Commitment in Dialogue, undertaken jointly with Erik Krabbe, explains several informal fallacies as shifts from one type of dialogue to another. The normative framework is that of a dialogue where two parties reason together, incurring and retracting commitments to various propositions as the dialogue continues. The fallacies studied include the ad hominem, the slippery slope, and many questions.

Asking the question, "Have you stopped cheating on your income tax returns?" is, by tradition, a classic case of the fallacy of many questions (complex question). However, in some contexts, asking such a question might not be fallacious. Suppose, for example, that the respondent has previously admitted, during cross-examination in the dialogue, to having cheated on her income tax returns in the past. If so, the question could be a reasonable one. If not, the question could be fallacious, or at least unreasonable to ask, and the respondent could legitimately reply to it by saying, "First, you should ask me whether I ever cheated on my income tax returns in the past."

Whether asking this question in a given case is fallacious or not, therefore, depends on the respondent's commitments, on what she is, or should be willing to accept, from what we know of her concessions in the context of dialogue for that case.

Note that whether asking the question is fallacious is not a function of what the questioner or respondent believes. It is a function of what the respondent should reasonably be prepared to accept, as far as we can judge this from what we know of the context of dialogue. In particular, what she conceded in answering previous questions in the dialogue is very important. Judging whether asking such a question is fallacious or not, in a given case, requires looking at the history of past exchanges between the two parties - the questioner and the respondent.

It has become increasingly widely accepted that informal logic requires a dialectification of logic whereby reasoning is seen as an interactive relationship between two (or among more than two) arguers. According to such a dialectical perspective, both participants take turns making moves, in the form of speech acts like questioning and replying. As these moves are made, the rules of dialogue should presumably determine which propositions a participant has become committed to in virtue of having made a particular type of move in a given dialogue-situation.

This much seems to be generally accepted by leaders in the informal logic movement, even if there remains plenty of room for disagreement on how such a program of dialectification is to be implemented - on what the precise rules are for a given type of argumentative dialogue, and so forth. But even this much of a revision in our perspective poses one central, major question.

What is commitment in dialogue? Is it a state of mind? Or is it an inference to be drawn from what you say and how you act when you are interacting with another participant in a social situation?

The first answer is a form of psychologism. The second represents the kind of 
viewpoint taken by Hamblin (1970), who described the commitment-set of a participant in reasoned dialogue as a kind of reconstructed profile or persona of a participant's beliefs. Essentially the same kind of viewpoint has been adopted by van Eemeren and Grootendorst (1984), who stress externalization as one of the chief features of their approach to argumentation. This means, according to van Eemeren and Grootendorst (1984, p. 7), that ". . . the argumentation theorist must concern himself with expressed opinions and argumentative statements and not primarily with the thoughts, ideas and motives which may underlie them."

The account of commitment in dialogue offered below-part of a larger research project undertaken jointly with Erik Krabbe-represents the second kind of viewpoint, advocated as an alternative to psychologism. ${ }^{1}$ However, it goes beyond the "externalized" notion of commitments as explicit concessions found in Hamblin and van Eemeren and Grootendorst by postulating non-explicit (dark) commitments that have to be inferred by presumption.

\section{Contexts of Dialogue}

The study of informal fallacies as significant errors of argumentation is made feasible by the pragmatic assumption that a given text of discourse containing an argument presupposes a context of dialogue. ${ }^{2}$ But there are many different contexts of argumentative dialogue, each of which has its own distinctive goals and rules.

In a persuasion dialogue, there are (basically) two participants, and the goal of each participant is to prove that his thesis, or point of view is right. The particular type of persuasion dialogue rightly emphasized by van Eemeren and Grootendorst (1984) as central for the normative study of fallacies is the critical discussion. In this type of dialogue, the proponent (protagonist) has the role of trying to show that his thesis is right, that it can be successfully argued for by the rules of the dialogue. The respondent (antagonist) has the role of asking critical questions to throw doubt on the proponent's argument for this thesis.

However, there are many other significant contexts of argumentative dialogue, aside from the critical discussion, that need to be considered in the study of the fallacies. A speech act that is overtly a warning, but covertly functions as a threat, could be quite out of place (even fallacious) if used as an argument in a critical discussion. Whereas the same speech act could be not contrary to the rules (nonfallacious) in the context of a negotiation. According to Donohue (1981), some kinds of threats can be legitimate argumentation tactics that contribute to the goals of negotiation dialogue.

Negotiation dialogue is a form of interest-based bargaining where the goal is for each party to try to "get the best deal." Moore (1986, p. 74) characterized this type of dialogue as a process wherein the participants make concessions to each other in order to try to maximize their own share of a given quantity of goods that is in too short a supply for all to have what they want. This type of argumentative dialogue is quite distinctively different from a critical discussion. The goal is not to show that a proposition can be argued for as right or true, based on relevant evidence. In negotiation dialogue, a commitment is not an assertion that some proposition is true. It is a concession or sacrifice of some goods or services (which may even be explicitly expressed in monetary terms) in order to encourage comparable concessions from the other side in the hopes of reaching a negotiated settlement.

Another kind of argumentative discussion is the debate. The debate shares some elements of the critical discussion, but its primary goal is not normally to resolve a conflict of opinions by reasoned arguments. The real goal of each participant is 
to persuade some third party (usually an audience or a designated referee) by arguments that can be persuasive without necessarily being very rational. $A$ debate often takes place in an institutionalized context, for example in a parliament, where the institutional rules can be highly permissive.

Highly emotional argumentation of questionable relevance to an issue may be allowed at some stages of a debate. In a debate, there is a strongly adversarial goal of winning over your opponent, even at the expense of logical reasoning, if your audience is not very interested in subtleties of logic. This doesn't mean that a debate has to be inherently illogical, or anything of this sort. But it does mean that the logical quality of debates can vary widely. A good debate should ideally approximate a critical discussion in important respects, but many debates are quite unlike what we rightly expect a critical discussion to be like.

Another context of argumentative dialogue is the inquiry or investigation. ${ }^{3}$ The inquiry is an essentially cumulative context of dialogue, meaning that retraction of commitments is not intended to be generally permitted. The goal of the inquiry is to prove a disputable or questionable proposition, if possible, by basing it on premises that can be established as known to be true. The intent is to try to minimize, or even eliminate, if possible, the need for later retractions. Alternatively, an inquiry seeks to establish that the existing evidence is insufficient to prove this particular proposition, to show that it cannot be proved, and must be regarded as unproven. Whichever outcome occurs, the inquiry seeks to go deeply enough into the existing evidence in order to establish one outcome or the other.

The inquiry is an essentially collaborative type of dialogue (unlike the debate). The inquiry is also a hierarchical type of argumentation where the premises are supposed to be known or established, and the conclusions to be drawn exclusively from these premises. The inquiry is essentially similar to an Aristotelian demonstration, where the premises are "prior to" or "better known than" the conclusion. According to the analysis of the fallacy of begging the question given in Walton (1991), circular argumentation generally tends to go against the goals of the inquiry, and is regarded as fallacious in that context.

Another kind of argumentative dialogue is the quarrel, where each participant is trying to "hit out" verbally at the other. The quarrel is characterized by truculence, high emotion, and a virtual absence of rules. It is, in effect, a kind of verbal combat to the death with no holds barred. Usually the participants in a quarrel regret their excesses afterwards, for the quarrel generates a lot of heat but very little light as far as reasoned discussion of an issue is concerned. The most valuable quality of a quarrel is that it can function as a means for giving vent to emotions. The quarrel tolerates irrelevant argumentation and also circular argumentation very well.

Other argumentative contexts of dialogue include the pedagogical dialogue, the planning committee dialogue, the interview, and the expert consultation. ${ }^{4}$

\section{Dialectical Shifts}

A cascading effect occurs when there is a multiple shift in a sequence of argumentation from one context of dialogue to another. For example, the following dialectical shift is often characteristic of cases of ad hominem argumentation.

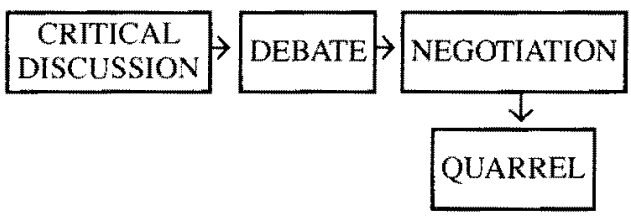

In this type of case, the dialogue may have started as a reasonable discussion of an issue and then progressively deteriorated into personal attacks and recriminations.

The fallacious argumentum ad hom. inem is often associated with a shift, or 
cascading of this type. For example, in the following parliamentary debate in the Question Period (Canada: House of Commons Debates, December 19, 1989, p. 7193), John Turner put forward a speech act that (overtly, at least) had the form of a question. However, Mr. Tumer's argumentation made no contribution to the debate at all. It was really a quarrelsome personal attack, made to hit out verbally at the Minister of Finance and his party.

\section{QUESTION PERIOD}

\section{[Translation]}

\section{PROPOSED GOODS AND SERVICES TAX (GST)}

\begin{abstract}
Right Hon. John N. Turner (Leader of the Opposition): Mr. Speaker, the Minister of Finance confirmed to us today that the goods and services tax he is preparing for us is in flagrant contradiction with all the election promises made by the Conservatives during the last election campaign. We know today that all the Conservatives" election promises were completely false.

The Minister said during the election campaign that the tax would be revenueneutral, that it would be brought in with the co-operation of the provinces, that it would be visible and the amount would appear on sales slips, that it would be easy to administer, that it would not be inflationary, that income tax rates for individuals would go down regardless of the rate set for the GST. Finally, Mr. Speaker, he said that the surtax on middle incomes would be abolished.

If the Minister really wants to reduce the deficit, if the Minister of Fiance really wants to control the deficit, why does he not apply the GST to all the lies the Conservatives told in the last election campaign? Then our deficit would disappear overnight.
\end{abstract}

Some Hon. Members: Hear, hear.

[English]

Mr. Mulroney: There's no question there. Put a question. What a farce.

Hon. Michael Wilson (Minister of Fiance): Mr. Speaker, I did not hear a question from the Right Hon. Leader of the Opposition.
Mr. Wilson (Etobicoke Centre): I did hear a lot of needless abuse. If we are going to have a debate on something like the GST, let's have a debate. We don't need this needless abuse.

\section{Some Hon. Members: Oh, oh!}

In this case, the respondents were justified in classifying the question as "abuse" rather than a contribution to the debate on the goods and services tax (GST).

It is this type of personal attack that is often associated with the shift to the quarrel, because it is very tempting for the respondent to reply (tu quoque) with a matching ad hominem attack. But the dialogue, in this case, is supposed to be a debate. From that point of view, the ad hominem shift to the quarrel can be evaluated as fallacious. Mr. Turner did utilize the supposed commitments of his opponents (by referring to their election promises) but not in a way that was appropriate for, or made any contribution to the debate on the GST.

\section{Explicit and Hidden Commitments}

As well as shifts to different types of dialogue, a kind of tightening up can occur within a single type of dialogue. In some cases, for example, a dialogue can begin as a relatively loose argumentative discussion where the rules are not applied rigorously. But then as the argument begins to tighten up, the participants may begin to insist on defining terms precisely, enforcing rules rigorously, insisting on the explicit statement of missing premises, and so forth. When such a tightening up has occurred, it may become more difficult for both participants to retract commitments freely in any situation. And participants are more likely to insist that commitments be explicit, as opposed to tacit presumptions or partly hidden commitments.

In the looser style of dialogue, characteristic of much everyday argumentation, commitments are often veiled, or only partly apparent to all the participants in a 
discussion. To model this idea, we can divide a Hamblin-type commitment set into two subsets-a light side of overt, expressed, explicit commitments, and a dark side of commitments that are only partially apparent or plausibly surmised by one or more of the participants in the dialogue. ${ }^{5}$ The dark side set is a definite set of propositions that exists (or is perhaps recorded or stored) somewhere. But it is said to be "dark," meaning that it is not known to be one participant's commitment by the other participant (or even, in some cases, by the holder himself). However, the other participant often has a pretty good idea of what she thinks this commitment amounts to. She can always put it to the test by asking the other party: "Are you committed to this or not?"

An example is the case of some critics who questioned the proposal of a vastly expanded national health-care system by the Heritage Foundation, a conservative think tank. These critics claim that real conservatives should be committed to opposing government bureaucracy where services can be provided by the private sector. The critics are alleging that there appears to be some sort of conflict of commitments in the conservative argument on health care. Defenders of the argument, however, claimed that what is needed is a kind of "progressive conservatism" or "capitalism with a big heart" as a way to allow for compassion in the conservative position. ${ }^{6}$

In this case, the precise implications of the underlying, general political commitment to conservatism in relation to the health care issue are not clear. What is involved is a dark-side commitment, yet it definitely has serious implications for the argument. There is even a presumption of inconsistency between the general position of conservatism and the specific policy on the health care issue advocated. This is enough tension to throw a burden of proof onto the Heritage Foundation's side of the dialogue, and throw it open to reasonable critical questions.
The critic's allegation of a conflict of commitments has "bite" because there is a general presumption in place to the effect that conservatives generally, as part of their conservative position (commitment), oppose expanding government services and functions where these services and functions can be taken care of by the private sector. To transfer health-care services from the private sector to government is a proposal that (subject to possible qualifications, exceptions, rebuttals, etc.) goes against that general presumption of commitment.

In this case, the dark-side commitment is inferred from what we know, or can reasonably presume about the conservative position generally, independently of what the Heritage Foundation might have gone on record as saying. But if the Foundation has made comments on health care in the past, inferences, either to dark or light-side commitments, could be drawn from these statements as well.

In this case, the critics can make a legitimate ad hominem attack on the Foundation by questioning the ostensible conflict of commitments. But the Foundation is free to reply, and may do so successfully or not. For more on the nature of conflicts of commitment, see Krabbe (1990).

\section{Clashing Commitments}

There can be various different kinds of clashing of commitments, but one of the most important is called incompatible commitments, where an individual is placed in a quandary because he cannot live up to two or more commitments in a given situation. ${ }^{7}$ Consider the case of Smith, who has a commitment to his family and a commitment to his job. He is needed as part of a team working to conclude a big business agreement on a particular day. In the midst of serious negotiations in which he is a key figure, a phone call message is relayed informing him that his young daughter in day care is sick and his imme- 
diate presence is required to take care of her.

Smith's commitments to his family and to his job do not clash per se. But in this case they have become incompatible in relation to a specific situation which may, in effect, test how those commitments are to be prioritized by Smith. Sometimes quandaries can be resolved by retracting commitments, or by various other ways of dealing with a specific problem. But generally, we should realize that it may not be possible to live up to, or fulfill all of one's previous commitments. At any rate, dealing with clashes of commitments is one of the major problems in the study of argumentative dialogue. To be revealed as inconsistent in one's commitments is not always totally devastating to one's position in reasonable dialogue, but it is a major problem to be contended with by a participant.

Suppose that Smith, in the past, had often made speeches to his wife on the subject of family values, saying that obligations to one's family ought to take priority over one's work, and over financial matters generally. Suppose further that Smith's wife now confronts him with his commitment to family, in relation to this specific question, given that Smith is arguing that he ought to stay in his business meeting to conclude the agreement, instead of going to the day care center. She is using the ad hominem argument, saying to Smith, "You don't practice what you preach!" In such a case, Smith's wife is raising the question of whether Smith was being honest or serious in his speeches on the importance of family values, in light of his proposed actions which appear to conflict with his expressed commitments. She is implying that Smith's action of staying at the meeting may be taken to imply, indirectly, by presumption, that Smith is more committed to his job than to his family.

Smith's wife's criticism alleges an implicit inconsistency between Smith's commitments by appealing to his implicit (dark-side) commitments revealed by his actions.

\section{Formal Modelling of Commitment}

The formal game of dialogue constructed by Hamblin $(1970$, p. 137) has as its purpose the "exchange of information" between the participants. But because this game lacked explicit win-loss rules (exchange of information was not precisely defined), there was no mechanism to fix commitment. A participant could conceivably persist in replying 'No commitment' to any question. ${ }^{8}$ This presents a basic problem in using Hamblin's formal structure as a framework of dialogue for the normative analysis of informal fallacies.

To deal with this problem several formal games of dialogue were constructed in Walton (1985, chapter 11) and Walton (1987, chapter 4) that had dark-side commitment sets as well as light-side sets. In these games, rules are included that penalize a player if he replies 'No commitment $\mathbf{A}^{\prime}$ ' when he really is committed to proposition $\mathbf{A}$ in the dialogue. For example, according to the rule (RDS) in Walton (1987, p. 249), if a player states 'No commitment $\mathbf{A}$,' and $\mathbf{A}$ is on the dark side of his commitment set, then $\mathbf{A}$ is immediately transferred to the light side of his commitment set. This can, in effect, be a sort of penalty because the offending player may not be able to retract his explicit commitment to $\mathbf{A}$ immediately, and $\mathbf{A}$ could then be used as a premise by the other participant. Since the purpose of such a game is to prove your own thesis from your adversary's commitments as premises, this could mean, in some situations, that the offending player could lose the game.

The formal mechanism in the dialogue could be called, for lack of a better term, a "commitment extractor" which is used by a critic to pull commitment from the dark side of another participant in a dialogue by aligning it with other (light-side) commit- 
ments of that participant. It is a kind of circumstantial ad hominem argument, but following the analysis of Walton (1985), such arguments can be nonfallacious in some cases. Whether the argument is reasonable or fallacious in this case depends on the context of dialogue, as inferred from the text of discourse, and in particular the commitments of the respondent, as far as these are known, or able to be inferred.

Of course, there can be many ways of formally modelling games of dialogue. But generally, the central problem for modelling commitment can be posed as follows. A participant should be committed to a proposition if he makes a move that, according to the rules, places certain propositions in his commitment set. For example, if a participant asserts $\mathbf{A}$, then $\mathbf{A}$ should be placed in his commitment set. If a questioner asks a question that has proposition $\mathbf{A}$ as a presupposition, and the respondent answers the question in the affirmative (without qualifications), then $\mathbf{A}$ is inserted into the respondent's commitment set. ${ }^{9}$ But under what conditions are retractions of commitments allowed? If a player asserts $\mathbf{A}$, but then later decides he is not committed to $\mathbf{A}$ any longer, can he retract? Or if a player is committed to $\mathbf{A}$, but then finds out that $\mathbf{A}$ implies $\mathbf{B}$, which he rejects, should or can he now retract his commitment to $\mathbf{A}$ ? However these decisions are made, the resulting rules will define a formal game of dialogue that may model some practical contexts of argumentative dialogue, but not others.

\section{Fallacies}

For some of us active in the informal logic movement, the study of formalized games of dialogue may seem too abstract to be useful in the practical job of analyzing and evaluating individual cases of argumentative discourse in everyday conversations. But in fact, the study of informal fallacies poses all sorts of important, hard questions that can only be ultimately resolved by appeal to a consideration of precise guidelines that are either partially formalized, or at least expressed in formalistic terms. This is so because normative models of reasonable dialogue are required in order to properly evaluate fallacious arguments as, in some appropriate senses, bad, weak, incorrect, or erroneous argumentation moves.

What this means is not that informal logic is really formal logic, only of a different kind than that stressed by the western traditions of symbolic logic and syllogistic logic. It simply means that informal logic has a structural or formalistic component, even though much of its task is concerned with the non-formalistic task of interpreting argumentative texts of discourse expressed in natural language dialogue (more a practical than a formalistic job). ${ }^{10}$

Consider a typical kind of case of the circumstantial ad hominem argument as an example. Suppose a reporter has heavily criticized politicians for unethical conduct in taking advantage of lucrative awards, big fees for speeches, expense-paid trips to Honolulu, and other benefits. But suppose also that this reporter is reminded that she has often taken advantage of the same kinds of benefits as a political and travel writer for her newsmagazine. The reporter, let's say, is attacked by the politician she had criticized, using the $t u$ quoque argument: "You are being hypocritical! How can you sincerely make these kinds of charges when you have engaged in the same conduct that you hold to be condemnable in my case." Here the ad hominem attack has been turned on its head in reply. ${ }^{11}$

What the politician is alleging in this ad hominem argument is that as far as one can judge from what she has said and done, she is apparently inconsistent in her commitments. She condemns such-andsuch practises in her words, but judging from her past actions, it would appear that 
either she is being inconsistent, or she is not really committed to the condemnation of these practises at all. In other words, there is an incompatibility between her explicit commitments expressed in her dialogue and her dark-side commitments which can plausibly be inferred or conjectured from her past actions.

But is she really inconsistent here (in the sense of there being a clash of commitments) or not? Formalistic models won't tell us, by themselves at any rate. We have to look at the individual case on its merits and carefully examine the text of discourse (what she said) in the context of the discussion. But in order to understand the sense in which she is said to be inconsistent, we have to recognize and understand the clash of commitments as an instance of incompatible commitments in dialogue. The advantage of commitment theory is that although what the reporter says and does are not, strictly speaking, logically inconsistent, what she does and says can be revealed as inconsistent commitments. Once dark-side commitments, as expressed indirectly by actions, for example, are taken into account, we can see how the circumstantial ad hominem argument has a basis for evaluation.

Another interesting aspect of ad hominem arguments already noted in section 2 is that they very often function as the mechanism that triggers a dialectical shiftfor example, from a critical discussion to a quarrel. This is one reason why ad hominem argumentation is particularly dangerous in reasoned dialogue, and often leads to a lowering of the quality of dialogue.

Other important fallacies related to the operation of commitments in dialogue include begging the question and slippery slope.

The problem of begging the question occurs in dialogue when a proponent tries to get a respondent to accept his (the proponent's) conclusion by "begging for it," i.e. trying to include it gratuitously in the premises of his argument instead of prov- ing it from premises that are already commitments of the respondent. See Walton (1991) for many cases to illustrate this analysis. Circular argumentation is not always fallacious, but using a circular argument to try to speciously avoid fulfilling one's burden of proof in begging the question is a deceptive, sophistical tactic that violates the rule of dialogue requiring a proponent to meet a burden of proof. The failure then, in such a case, is not one of using an invalid argument. It is one of inappropriately attempting to utilize a proposition as a premise in an argument - a proposition that is not really a commitment of the respondent to whom the conclusion is supposed to be proved.

Closely related to analyzing particular cases of begging the question is the problem of identifying non-explicit premises. ${ }^{12}$ And, of course, this is where the distinction between light-side and dark-side commitments becomes vital in any theory of argument that can successfully be applied to working cases. It is here especially where the explicitization of commitment in the account of van Eemeren and Grootendorst (1984) could be broadened to include dark-side commitments in argumentation.

\section{Slippery Slope Argumentation}

A slippery slope argument occurs in a context of dialogue where a respondent has advocated a particular policy or course of action and a proponent counsels against it, using the following negative type of argumentation: "Once you take the first step, and thereby become committed to this policy, it will lead to a similar, closely connected step which you will have become committed to by taking the first step. This will lead to a sequence of other closely similar pairs of cases, until you arrive at some horrible or intolerable outcome. Therefore, you must not take this first step." This kind of argumentation is a species of gradualistic linkage of an arguer's commit- 
ments by a proponent who has the goal of dissuading that arguer from a contemplated course of action. ${ }^{13}$

One problem with slippery slope arguments is that they are often sketchy and incomplete-see Johnson and Blair (1983, pp. 160-169) -with the result that they are not so much fallacious as weak arguments, arguments that lack adequate justification in a context of dialogue. The problem is to fill out the missing premises by determining (in discussion) what an arguer's commitment implies, by virtue of its being closely similar (analogous) to another case. This involves case-based reasoning by analogy. ${ }^{14}$ But it also involves determining what the implications of an arguer's commitments really are. The problem is basically one of commitment in dialogue, but the slippery slope argument is distinctive in that it involves the attempt to argue from commitments by a series of small steps, gradually by closely linked cases, in a way that is particularly difficult to resist (Walton, 1992).

Generally in a critical discussion, a participant's argumentation is based on premises that are commitments of the other participant. The arguers are "reasoning together," so to speak. A good deal of such argumentation takes the form of refutation, where one party takes a set of premises that are all commitments of the second party, and derives conclusions (using the accepted warrants of inference) that the second party is clearly committed to rejecting. This type of argumentation has the same general structure as reductio ad absurdum, a kind of inference widely recognized in formal logic.

Slippery slope argumentation is a special kind of refutation. What makes it distinctive is its use of the technique of gradualism, by breaking up the sequence of argumentation into small steps. The tactic is one of forcing commitment by arguing, "You accepted the last step, and this next step is so close to it, without any definable difference, that if you don't accept it, you must be inconsistent in your commitments." Thus whether or not a slippery slope argument is correctly or fallaciously used (a sophistical refutation) depends on the respondent's commitments, and on what they may be taken to imply.

\section{The Maieutic Function of Dialogue}

The goal of a critical discussion is to resolve a conflict of opinions by rational means. But in practice, too often critical discussions on politics, ethics, and other controversial issues, fail to result in a clear-cut resolution of the issue. Even so, such a discussion can be very valuable, it is often conceded, in virtue of its having revealed the commitments of the participants more fully.

This value of increased insight into one's own position was called "self-knowledge" by Socrates, and his professed skill as a philosopher was to be able to assist in the "birth" of new ideas by others, by questioning them in dialogue. This capability to reveal previously hidden commitments could be called the maieutic function of dialogue-maieutikos means 'skill in midwifery' in Greek.

It ought to be stressed here that the maieutic function of dialogue is an important side-benefit of a good critical discussion. $B y$ revealing the fallacies and logical faults in his arguments on an issue, a critical discussion can prepare the way for knowledge by clarifying an argument's commitments.

Since the condemnation of the sophists, the popular climate of opinion is to question or reject the value of critical discussion, saying, for example: "What is the use of arguing this side and that side of a controversial issue. You can go on and on, citing arguments for and against each side. but you never really come to a definite conclusion. You're no better off than when you started." The feeling is that in a scientific inquiry, you can get down to "hard evidence" - by using exact methods you 
can establish a conclusion, and so this kind of argumentation results in knowledge. Critical discussion, by contrast, it is felt, is "subjective," and does not result in definite knowledge.

The objection at the basis of this skeptical point of view is partly accurate. Critical discussion on controversial issues uses argumentation based on commitments of the participants that are not items of hard knowledge, but are, at best, plausible presumptions. But, in another respect, this skeptical point of view overlooks the most important value of critical discussion by portraying it as something it was not, nor should ever have been designed to behard knowledge about empirical facts or mathematical calculations.

Critical discussion has the goal of resolving conflicts of opinion. But it also has the important value (side-benefit) of allowing each participant to articulate his or her deeply held commitments more clearly by testing them in argumentation with others who hold opposed points of view. ${ }^{15}$ The real value in such a dialogue comes in through the side door. Such discussion can prepare the way for knowledge by revealing the fallacies and logical weaknesses in a participant's arguments, and by revealing the reasoning behind his or her commitments.

While it should not be regarded as a substitute for empirical investigation, critical discussion of controversial issues can provide insight into one's own deeply held, personal commitments. At the same time, it can lead to respect for opposing points of view (tolerance), and to a respect for the fallibility of argumentation in the human situation (revealing of dogmatism).

The negotiation and inquiry types of dialogue need no justification in current popular pieties and economic policies. They have clear and evident economic benefits. The value of critical discussion is more subtle and less evident, it seems, from a point of view of twentieth century preconceptions of what is important.

To bring out this important maieutic benefit of critical discussion, and at the same time provide better analyses of the fallacies, it needs to be recognized that the concept of dark-side commitment is essential as part of the critical discussion as a type of dialogue. One can see why, in first introducing the critical discussion as a normative model of dialogue, it was perceived as favorable to stress the externalized nature of commitment, as expressed in explicit assertions and the like. Dark-side commitments seem fuzzy and, well, "dark." But to make the critical discussion a normative model that is practically useful in analyzing and evaluating fallacies and other aspects of everyday argumentation on controversial subjects, it is vitally important to bring in this new idea.

\section{Notes}

This is a revised version of a paper presented at the Third International Symposium on Informal Logic held at the University of Windsor in June 1989. Research for this paper was supported by three awards: (1) a Killam Research Fellowship awarded by the Killam Foundation through the Canada Council; (2) a Fellowship from the Netherlands Institute for Advanced Study in the Humanities and Social Sciences; and (3) a Research Grant from the Social Sciences and Humanities Research Council of Canada.

2 Van Eemeren (1986).
3 Walton (1989).

4 These types of dialogue are classified and elaborated on in the forthcoming joint research monograph with Erik Krabbe, Commitment in Dialogue.

5 Walton (1987, p. 142).

6 See Trudy Govier, "Analogies and Missing Premisses," Informal Logic, 11 (1989) 141-52.

7 See Krabbe (1990).

8 See the comments in Walton (1987, p. 106). 
9 See Douglas N. Walton, Question-Reply Argumentation, Westport, Connecticut, Greenwood Press, 1989.

10 See van Eemeren (1986).

11 For a similar case, see Walton (1985, Appendix 1).

12 See van Eemeren and Grootendorst (1984).

13 Govier (1982) and Walton (1992).
14 See Trudy Govier, "Analogies and Missing Premisses," Informal Logic, II (1989) 141-52.

1.5 Robinson (1953) describes how, in the early Platonic dialogues, an elenchtic questioner (Socrates) assists his respondents in dialogue to give birth to personal insights that are a form of revelation or deepened understanding for them, and for all who read the dialogues.

\section{References}

Else Barth and Erik C. W. Krabbe, From Axiom to Dialogue, New York, de Gruyter, 1982.

Eleanor Clift, 'Conservatives Learn to Love Big Government,' Newsweek, July 10, 1989, p. 20.

William A. Donohue, 'Analyzing Negotiation Tactics: Development of a Negotiation Interact System,' Human Communication Research, 7 , 1981, 237-287.

Trudy Govier, 'What's Wrong with Slippery Slope Arguments?' Canadian Journal of Philosophy, 12, 1982, 303-316.

Charles L. Hamblin, Fallacies, London, Methuen, 1970.

Ralph H. Johnson and J. Anthony Blair, Logical Self-Defense, 2nd ed., Toronto, McGraw-Hill Ryerson, 1983.

Erik C. W. Krabbe, 'Inconsistent Commitment and Commitment to Inconsistencies,' Informal Logic, 12, 1990, 33-42.

Christopher W. Moore, The Mediation Process, San Francisco, Jossey-Bass Publishers, 1986.
Richard Robinson, Plato's Earlier Dialectic, Oxford, Oxford University Press, 1953.

Frans H. van Eemeren, 'Dialectical Analysis as a Normative Reconstruction of Argumentative Discourse, Text, 6, 1986, 1-16.

Frans H. van Eemeren and Rob Grootendorst, Speech Acts in Argumentative Discussions, Dordrecht, Foris, 1984.

Douglas N. Walton, Arguer's Position, Westport, Connecticut, Greenwood Press, 1985.

Douglas N. Walton, Informal Fallacies, Amsterdam, Benjamins, 1987.

Douglas N. Walton, Begging the Question, New York, Greenwood Press, 1991.

Douglas Walton, Slippery Slope Arguments, Oxford, Clarendon Press, 1992.

DOUGLAS WALTON

DEPARTMENT OF PHLLOSOPHY

UNIVERSITY OF WINNIPEG

WINNIPEG, MANITOBA R3B $2 E 9$ 